\title{
Intravenous Human Umbilical Cord-Derived Mesenchymal Stromal Cell Administration in Models of Moderate and Severe Intracerebral Hemorrhage
}

\author{
Tanira Giara Mello, ${ }^{1-3}$ Paulo Henrique Rosado-de-Castro, ${ }^{3-5}$ \\ Raquel Maria Pereira Campos, Juliana Ferreira Vasques, ${ }^{1,3}$ William Simões Rangel-Junior,1, \\ Raphael Santos de Almeida Rezende de Mattos, Teresa Puig-Pijuan, ${ }^{1,3}$ Bernd Uwe Foerster, \\ Bianca Gutfilen, ${ }^{4}$ Sergio Augusto Lopes Souza, ${ }^{4}$ Johannes Boltze, ${ }^{7}$ Fernando Fernandes Paiva, ${ }^{6}$ \\ Rosalia Mendez-Otero, ${ }^{1,3, *}$ and Pedro Moreno Pimentel-Coelho ${ }^{1,3, *}$
}

Intracerebral hemorrhage (ICH) is as a life-threatening condition that can occur in young adults, often causing long-term disability. Recent preclinical data suggest mesenchymal stromal cell (MSC)-based therapies as promising options to minimize brain damage after ICH. However, therapeutic evidence and mechanistic insights are still limited, particularly when compared with other disorders such as ischemic stroke. Herein, we employed a model of collagenase-induced ICH in young adult rats to investigate the potential therapeutic effects of an intravenous injection of human umbilical cord Wharton's jelly-derived MSCs (hUC-MSCs). Two doses of collagenase were used to cause moderate or severe hemorrhages. Magnetic resonance imaging showed that animals treated with hUC-MSCs after moderate ICH had smaller residual hematoma volumes than vehicletreated rats, whereas the cell therapy failed to decrease the hematoma volume in animals with a severe ICH. Functional assessments (rotarod and elevated body swing tests) were performed for up to 21 days after ICH. Enduring neurological impairments were seen only in animals subjected to severe ICH, but the cell therapy did not induce statistically significant improvements in the functional recovery. The biodistribution of Technetium99m-labeled hUC-MSCs was also evaluated, showing that most cells were found in organs such as the spleen and lungs $24 \mathrm{~h}$ after transplantation. Nevertheless, it was possible to detect a weak signal in the brain, which was higher in the ipsilateral hemisphere of rats subjected to a severe ICH. These data indicate that hUC-MSCs have moderately beneficial effects in cases of less severe brain hemorrhages in rats by decreasing the residual hematoma volume, and that optimization of the therapy is still necessary.

Keywords: cell therapy, stem cells, mesenchymal stromal cells, Wharton's jelly, hemorrhagic stroke, intracerebral hemorrhage

\section{Introduction}

$\mathrm{T}^{\mathrm{s}}$ HE ABSOLUTE NUMBER of stroke survivors and of people living with disability after stroke has increased in the last few decades [1]. It has been estimated that the global lifetime risk of stroke among adults aged $\geq 25$ years is $18.3 \%$ for ischemic stroke and $8.2 \%$ for hemorrhagic stroke [2]. Al- though the likelihood of having a hemorrhagic stroke increases with aging, recent research has begun to draw attention to nontraumatic intracerebral hemorrhage (ICH) in young and middle-aged adults ( $<50$ years of age), due to its particularities and major socioeconomic consequences. ICH in this group has an annual incidence of 4.9 per 100,000 individuals and is more often associated with a poor long-

\footnotetext{
${ }^{1}$ Instituto de Biofísica Carlos Chagas Filho and ${ }^{5}$ Instituto de Ciências Biomédicas, Universidade Federal do Rio de Janeiro, Rio de Janeiro, Brazil.

${ }^{2}$ Instituto de Engenharia Nuclear, Comissão Nacional de Energia Nuclear, Rio de Janeiro, Brazil.

${ }^{3}$ Instituto Nacional de Ciência e Tecnologia em Medicina Regenerativa, Rio de Janeiro, Brazil.

${ }^{4}$ Departamento de Radiologia, Faculdade de Medicina, Universidade Federal do Rio de Janeiro, Rio de Janeiro, Brazil.

${ }^{6}$ Instituto de Física de São Carlos, Universidade de São Paulo, São Carlos, Brazil.

${ }^{7}$ School of Life Sciences, University of Warwick, Coventry, United Kingdom.

*These authors contributed equally to this work.
} 
term functional outcome than ischemic stroke [3-5]. For instance, Koivunen et al. reported an unfavorable outcome in $48.9 \%$ of the survivors of ICH at a young age [6].

While current therapeutic options for ischemic stroke are focused on the restoration of cerebral blood flow and protection of the ischemic penumbra [7], treatment of ICH is mainly based on supportive care, management of coagulopathy, and blood pressure control, with surgical approaches for hematoma evacuation being reserved for selected cases [8]. The identification of mechanisms of secondary brain injury after $\mathrm{ICH}$, such as inflammation and the toxicity of blood products, has led to a large number of preclinical studies focused on immunomodulation and hematoma resolution [9-11]. Recent clinical trials, however, have failed to recapitulate the benefit of several pharmacological and surgical therapies in patients with $\mathrm{ICH}$, although only a few young patients have been included in these trials [4,9].

It has also been suggested that mesenchymal stromal cell (MSC)-based therapies would represent promising strategies for treating ICH patients, by targeting multiple mechanisms of brain injury $[12,13]$. Treatments based on human or murine bone marrow-derived MSCs (BM-MSCs), for instance, have been shown to have anti-inflammatory and neuroprotective effects in models of ICH [14]. Compared with BM-MSCs, however, human umbilical cord Wharton's jelly-derived MSCs (hUCMSCs) offer the advantages of being easily obtained from a routinely discarded tissue without the need of an invasive procedure, having a high harvest rate and exhibiting a greater proliferative activity in vitro [15]. Moreover, BM-MSCs and hUC-MSCs have distinctive transcriptional profiles [16,17] and secretomes [18-20]. Although systemic hUC-MSC administration has been widely used in preclinical and clinical studies for other conditions, including ischemic stroke [21], the preclinical efficacy of hUC-MSCs in ICH has so far only been assessed in a few studies. Most of these studies used the intracerebral route for cell administration [22-25], which is a complex and invasive procedure not entirely free of complications [26]. In addition, it is not known whether ICH severity affects hUC-MSC-based treatments. In this study, we used collagenase-induced models of moderate and severe $\mathrm{ICH}$ ( $\mathrm{mICH}$ and $\mathrm{sICH}$, respectively) to address these translationally relevant points.

\section{Materials and Methods}

\section{Animals}

Male Wistar rats aged 7-10 weeks and weighing 335$435 \mathrm{~g}$ (mean age: $55 \pm 7$ days) were used in this study. The emergence of adult-type behaviors was reported to occur around this age in rodents (postnatal day 60 in rodents, corresponding to $>20$ years in humans) [27]. All procedures were approved and conducted in accordance with the Animal Care and Use Committee at the Universidade Federal do Rio de Janeiro (protocol number 111/14). All animals received humane care in compliance with the "Principles of Laboratory Animal Care" formulated by the National Society for Medical Research and the U.S. National Academy of Sciences Guide for the Care and Use of Laboratory Animals.

\section{ICH model}

In this study, we used the model of collagenase-induced spontaneous ICH developed by Rosenberg et al. [28], with minor modifications. For analgesia, rats were given an intraperitoneal injection of tramadol $(12.5 \mathrm{mg} / \mathrm{kg}) 15 \mathrm{~min}$ before anesthesia. The animals were anesthetized through an intraperitoneal injection of xylazine hydrochloride $(15 \mathrm{mg} /$ $\mathrm{kg}$ ) and ketamine hydrochloride $(100 \mathrm{mg} / \mathrm{kg})$, and were then placed in a stereotaxic apparatus. An intradermal injection of lidocaine $(5 \mathrm{mg} / \mathrm{kg})$ was administered before an incision was made along the longitudinal midline of the scalp [29]. Bregma was located, and a hole $\sim 1.5 \mathrm{~mm}$ in diameter was drilled in the skull to allow the introduction of a 26-gauge needle attached to a $10-\mu \mathrm{L}$ syringe (Hamilton) into the left striatum $(3 \mathrm{~mm}$ lateral to midline, $0.2 \mathrm{~mm}$ posterior to bregma, $6 \mathrm{~mm}$ below the surface of the skull) [30,31]. Two microliters of sterile saline containing 0.1 or $0.25 \mathrm{U}$ of bacterial collagenase IV-S (Sigma-Aldrich) or the same volume of the vehicle (sham group) was then injected at a constant rate of $0.25 \mu \mathrm{L} / \mathrm{min}$ using a microinfusion pump (Harvard Apparatus) [31]. After infusion, the needle was left in place for $10 \mathrm{~min}$, and then withdrawn slowly to prevent backflow. The burr hole was sealed with dental cement, the skin was sutured, and rats were placed in clean cages with free access to food and water. Normothermia was maintained during and after surgery using a heating pad and heating lamps.

\section{hUC-MSC isolation and culture}

Umbilical cords were collected from term deliveries after the informed consent forms were signed by the mothers. This procedure was approved by the Institutional Ethics Committee of the Universidade Federal do Rio de Janeiro. hUC-MSCs were isolated as previously described [32]. In brief, cords were cut into smaller pieces, and dissected for the removal of the arteries and the vein, leaving only the Wharton's jelly. The remaining tissue was then digested with collagenase II (200 U/mL; Gibco) diluted in phosphatebuffered saline (PBS) for $16 \mathrm{~h}$ at $37^{\circ} \mathrm{C}$ under slow stirring. The digested material was washed in PBS and plated in Dulbecco's modified Eagle's medium:nutrient mixture F-12 (DMEM/F12; Invitrogen) culture medium supplemented with $15 \%$ fetal bovine serum (FBS; Invitrogen) and $1 \%$ penicillin/streptomycin (Gibco). Cells were kept at $37^{\circ} \mathrm{C}$ in an incubator with $5 \% \mathrm{CO}_{2}$. After reaching confluence, cells were enzymatically dissociated by incubation with a trypsin solution ( $0.25 \%$ trypsin $+1 \mathrm{mM}$ EDTA; Gibco) for $5 \mathrm{~min}$. For cryopreservation, cells at passage numbers 3-5 were resuspended in FBS containing $10 \%$ dimethyl sulfoxide (Sigma-Aldrich), and frozen in liquid nitrogen. We used hUC-MSCs from a single donor to reduce donor-related variability. The MSC identity was confirmed by evaluating the expression of cell-surface markers by flow cytometry, as demonstrated in our previous study [32], as well as by assessing their capacity to differentiate into cells of the mesoderm lineage (data not shown).

\section{hUC-MSC administration}

On the day of injection, vials containing hUC-MSCs were defrosted. Cells were then centrifuged at $300 \mathrm{~g}$ for $5 \mathrm{~min}$, washed $3 \times$ with PBS containing Pulmozyme (recombinant human DNase I; $0.6 \mu \mathrm{L} / \mathrm{mL}$; Roche), and resuspended in PBS+Pulmozyme. A small fraction of cells was stained with trypan blue to assess cell viability and concentration. 
Animals were randomly allocated to receive either $3 \times 10^{6}$ hUC-MSCs (suspended in $0.5 \mathrm{~mL}$ of PBS+Pulmozyme) or the same volume of the vehicle through the tail vein, infused over 2-3 min, $24 \mathrm{~h}$ after ICH. This dosage was chosen based on the doses used in studies that investigated the effects of bone marrow-derived MSCs in models of ICH [14]. Pulmozyme was used to avoid MSC aggregation, as described previously [33]. Sham-operated animals received an intravenous injection of the same volume of the vehicle $24 \mathrm{~h}$ after the surgical procedure.

\section{Rotarod performance test}

The rotarod test was employed to assess motor coordination and balance. Animals were pretested by an examiner blinded to treatment allocation 2 days before ICH induction, and then tested on days 3, 7, 14, and 20 after ICH. The animals were placed in a neutral position, and the rod was set to accelerate from 8 to $37 \mathrm{rpm}$ in $320 \mathrm{~s}$. Rats were subjected to three trials per session, at an interval of 5 min between each trial. The time spent on the rotarod (i.e., the latency to fall) was recorded in each trial. Rats remaining on the rotarod for $>420$ s were removed, and their latency to fall was recorded as $420 \mathrm{~s}$. For statistical analysis, the best trial (i.e., the longest time spent on the rotarod) was chosen for each animal.

\section{Elevated body swing test}

The elevated body swing test was performed by an examiner blinded to treatment allocation for the measurement of asymmetrical motor behavior, as described by Borlongan and Sanberg [34]. Animals were pretested 1 day before ICH induction, and then tested on days $1,8,15$, and 21 after ICH. In brief, animals were suspended in the air by the tail, and the direction of body swing ("a $>10^{\circ}$ bending of the upper body out of the vertical axis to either side" [35]) was recorded in four blocks of five consecutive trials, with $5 \mathrm{~min}$ intervals between the blocks. The percentage of right-side swings in 20 trials was quantified.

\section{Magnetic resonance imaging}

Magnetic resonance imaging (MRI) was used to measure the volume of the residual hematoma and hemispheric atrophy. On day 22 after $\mathrm{ICH}$, rats were deeply anesthetized through an intraperitoneal injection of a mixture of xylazine hydrochloride $(15 \mathrm{mg} / \mathrm{kg})$ and ketamine hydrochloride $(100 \mathrm{mg} / \mathrm{kg})$, and then transcardially perfused with ice-cold $0.9 \%$ saline, followed by $4 \%$ paraformaldehyde (PFA) in phosphate buffer, $\mathrm{pH}$ 7.4. The heads were kept in $4 \%$ PFA until image acquisition.

For the model of $\mathrm{mICH}$, MRI was carried out in a 7.0 Tesla Magnetic Resonance System (7 T/400 horizontal Varian scanner; Agilent Technologies) at the Centro Nacional de Biologia Estrutural e Bioimagem (CENABIO). T1- and $\mathrm{T} 2 *$-weighted $3 \mathrm{D}$ sequences were acquired using the same geometric parameters: field of view $(\mathrm{FOV})=32 \times$ $32 \times 32 \mathrm{~mm}$ with a matrix of $128 \times 128 \times 128$, resulting in an isotropic spatial resolution of $250 \mu \mathrm{m}$. The images were reconstructed using zero filling for a $256 \times 256 \times 256$ matrix. T1-weighted images were acquired with a gradient echo (GRE) sequence with the following parameters: echo time/ repetition time $(\mathrm{TE} / \mathrm{TR})=5 / 50 \mathrm{~ms}$, flip angle $=20^{\circ}$, band- width $=15 \mathrm{kHz} . \mathrm{T} 2 *$-weighted images were acquired with GRE sequence with the following parameters: TE/TR $=15$ / $500 \mathrm{~ms}$, flip angle $=20^{\circ}$, bandwidth $=15 \mathrm{kHz}$. The residual hematoma volume and the volume of cerebral hemispheres were calculated using the OsiriX software (OsiriX 4.0; Pixmeo SARL) by an examiner blinded to treatment allocation. To evaluate the residual hematoma volume, the region of interest (ROI) was marked around the residual hematoma in all coronal sections where it was visible. The volume of cerebral hemispheres was calculated by measuring the surface area of each hemisphere in 40 coronal sections starting from the following stereotaxic coordinate: anterior/posterior (AP) $+2.2 \mathrm{~mm}$ from bregma, which spanned the area where the hematoma was present in all animals.

For the model of sICH, MRI was carried out in a 2.0 Tesla Magnetic Resonance System composed of an Oxford Instruments $85310 \mathrm{HR}$ Magnet (Oxford Instruments) and Bruker Avance AVIII console (Bruker-Biospin) at the Instituto de Física de São Carlos, Universidade de São Paulo. A locally developed solenoid coil was used as a transmission and reception coil. T1-, T2-, and T2*-weighted 3D sequences were acquired using the same geometric parameters: $F O V=32 \times$ $32 \times 32 \mathrm{~mm}$ with a matrix of $128 \times 128 \times 128$, resulting in an isotropic spatial resolution of $250 \mu \mathrm{m}$. The images were reconstructed using zero filling for a $256 \times 256 \times 256$ matrix. T1-weighted images were acquired with a GRE sequence with the following parameters: $T E / T R=15 / 3.5 \mathrm{~ms}$, flip angle $=30^{\circ}$, bandwidth $=15 \mathrm{kHz}$. T2-weighted images were acquired using a reverse fast imaging with steady-state free precession (PSIF) sequence with the following parameters: TR/TE: $24 / 7 \mathrm{~ms}$, flip angle $=60^{\circ}$, bandwidth $=15 \mathrm{kHz}$. Finally, T2*-weighted images were acquired with GRE sequence with the following parameters: TE/TR $=20 / 10.5 \mathrm{~ms}$, flip angle $=5^{\circ}$, bandwidth $=15 \mathrm{kHz}$. The residual hematoma volume and the volume of cerebral hemispheres were calculated using the Medical Image Processing, Analysis, and Visualization application (MIPAV 8.0.2; National Institute of Health) by an examiner blinded to treatment allocation. To evaluate the residual hematoma volume, the ROI was marked around the residual hematoma in all coronal sections where it was visible. The volume of cerebral hemispheres was calculated by measuring the surface area of each hemisphere in 50 coronal sections starting from the following stereotaxic coordinate: AP $+2.2 \mathrm{~mm}$ from bregma, which spanned the area where the hematoma was present in all animals.

\section{Experimental design}

Sham group. Ten rats were randomly allocated to the sham group. Animals from the sham group received an intrastriatal injection of saline, followed by an intravenous injection of saline $24 \mathrm{~h}$ later. No deaths occurred in the sham group during the 22-day follow-up period. Behavioral assessments were performed as described above in all animals (Fig. 1).

$m I C H$. Twenty-four rats received an intrastriatal injection of $0.1 \mathrm{U}$ collagenase into the left striatum to induce a $\mathrm{mICH}$. Four rats died within the first $24 \mathrm{~h}$ after the surgery, and the remaining 20 animals were randomly selected to receive either a single intravenous injection of $3 \times 10^{6}$ hUC-MSCs (mICH+hUC-MSC group; $n=10)$ or of the vehicle (mICH+ Vehicle group; $n=10$ ). These animals were followed up for a 


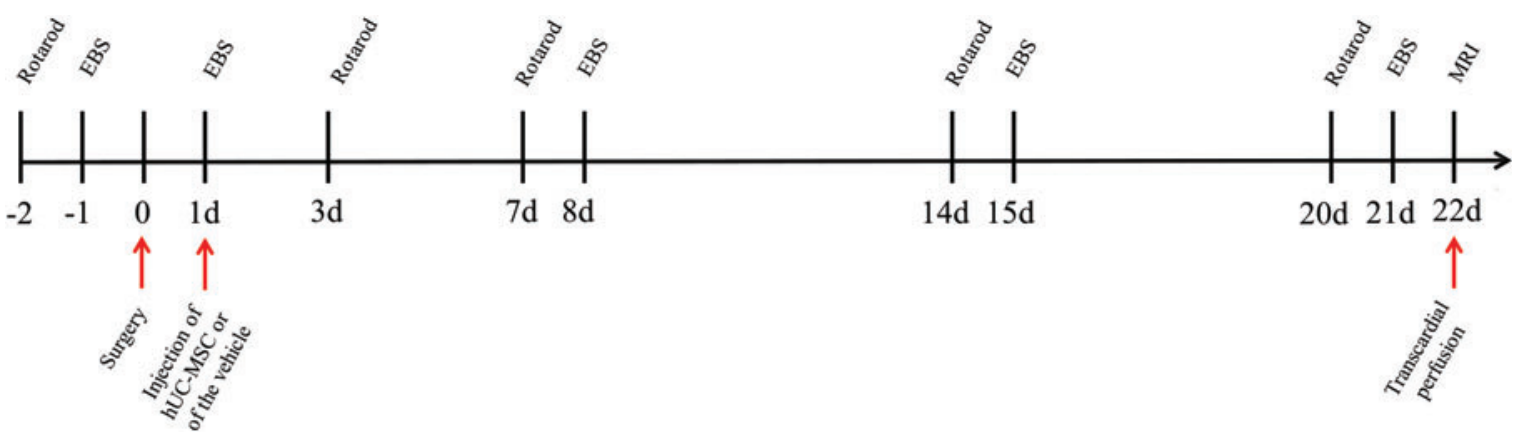

FIG. 1. Experimental design. EBS, elevated body swing test; hUC-MSC, human umbilical cord Wharton's jelly-derived mesenchymal stromal cells; MRI, magnetic resonance imaging. Color images are available online.

period of 22 days, during which no deaths occurred. Behavioral assessments were performed as described above in all animals, but 1 animal from the mICH+Vehicle and 2 animals from the $\mathrm{mICH}+\mathrm{hUC}-\mathrm{MSC}$ group were excluded from the rotarod analysis due to a technical problem. One animal from the $\mathrm{mICH}+$ Vehicle group was excluded from the study due to the absence of a visible hematoma on MRI.

sICH. Forty-seven rats received an intrastriatal injection of $0.25 \mathrm{U}$ collagenase in the left striatum to model a sICH. Nineteen rats died within the first $24 \mathrm{~h}$ after the surgery, and the remaining 28 animals were randomly selected to receive either a single intravenous injection of $3 \times 10^{6} \mathrm{hUC}$ MSCs (sICH+hUC-MSC group; $n=13$ ) or of the vehicle (sICH+Vehicle group; $n=15)$. These animals were followed up for a period of 22 days, during which one death occurred in the sICH+Vehicle group (within $24 \mathrm{~h}$ after the intravenous infusion of the vehicle), and no deaths were registered in the sICH+hUC-MSC group. Behavioral assessments were performed as described above in all animals. One animal from the mICH+hUC-MSC group was excluded from the study due to the wrong location of the hematoma on MRI.

\section{Biodistribution analysis}

The biodistribution of MSCs was evaluated in a separate cohort of animals. The cells were labeled with ${ }^{99 \mathrm{~m}}$ Technetium $\left({ }^{99 \mathrm{~m}} \mathrm{Tc}\right)$ before the injection into animals from the following experimental groups: rats subjected to collagenase-induced $\mathrm{mICH}$ and sICH, sham-operated rats, and naïve (unmanipulated) rats ( $n=5-6$ per group). Two hours after cell injection, whole-body scintigraphy was carried out in a gamma camera (General Electric Medical Systems) equipped with a lowenergy, high-resolution collimator. A $15 \%$ energy window centered on the $140 \mathrm{keV}$ photopeak of ${ }^{99 \mathrm{~m}} \mathrm{Tc}$ was selected. Rats were euthanized as described above $24 \mathrm{~h}$ after ${ }^{99 \mathrm{~m}} \mathrm{Tc}$ labeled hUC-MSC ( ${ }^{99 \mathrm{~m}}$ Tc-hUC-MSC) transplantation. The cerebral hemispheres, heart, lungs, liver, kidneys, intestines, and spleen were removed and weighed. The radioactivity was measured using a gamma well counter (multicrystal LB 2111 gamma counter; Berthold Technologies), and the percentage of injected dose per gram of organ $(\% \mathrm{ID} / \mathrm{g})$ was determined for each sample, as described previously [36].

\section{Luminex ${ }^{\circledR}$ assay}

The immunomodulatory activity of MSCs was evaluated in a separate cohort of animals ( $n=6-7$ per group). Forty-eight hours after sham operation or ICH induction $(24 \mathrm{~h}$ after the intravenous injection of hUC-MSCs or of the vehicle) rats were deeply anesthetized through an intraperitoneal injection of a mixture of xylazine hydrochloride $(15 \mathrm{mg} / \mathrm{kg})$ and ketamine hydrochloride $(100 \mathrm{mg} / \mathrm{kg})$. Rats were then transcardially perfused with ice-cold $0.9 \%$ saline, and the ipsilateral brain hemispheres were collected and stored at $-80^{\circ} \mathrm{C}$. Tissues were homogenized in buffer $(150 \mathrm{mM} \mathrm{NaCl}, 25 \mathrm{mM}$ Tris, $\mathrm{pH} 7.4,1 \%$ Triton $\mathrm{X}-100)$ containing a protease inhibitor cocktail (Promega). Total protein levels in the supernatants were measured using the Pierce ${ }^{\mathrm{TM}} \mathrm{BCA}$ protein assay kit (Thermo-Fisher Scientific). The Milliplex MAP Rat Cytokine/Chemokine Magnetic Bead Panel (RECYTMAG-65K; Millipore) was used to quantify the levels of monocyte chemoattractant protein-1 (MCP-1), interleukin-1 $\beta$ (IL-1 $\beta$ ), IL-6, and IL-10 in the samples according to the manufacturer's instructions. Assay plates were immediately read and analyzed on a Luminex ${ }^{\circledR}$ MAGPIX system (Millipore). All samples and standards were measured in duplicate.

\section{Statistical analysis}

Statistical analysis was performed using GraphPad Prism version 6.01 (GraphPad Software). Intergroup comparisons were performed by two-way analysis of variance (ANOVA) with repeated-measures and Tukey's multiple comparison post hoc test (rotarod and elevated body swing tests), twoway ANOVA with Bonferroni's multiple comparison post hoc test (biodistribution analysis), one-way ANOVA with Bonferroni's post hoc test (Luminex ${ }^{\circledR}$ assay), or Student's $t$-test (MRI data analysis; after confirming the normality of the data using the D'Agostino-Pearson omnibus normality test), as indicated. The observed differences were considered significant when $P<0.05$.

\section{Results}

\section{Functional assessment}

We first investigated whether ICH would cause long-term behavioral deficits in young rats, and whether hUC-MSCs would foster recovery.

The rotarod performance test was used to evaluate motor coordination on days 3, 7, 14, and 20 after surgery. Also, a baseline assessment was performed 2 days before surgery (Fig. 1). First, using a model of $\mathrm{mICH}$, we compared the latency to fall between sham-operated animals (Sham), rats subjected to $\mathrm{ICH}$ and treated with the vehicle $(\mathrm{mICH}+\mathrm{Ve}-$ hicle), and animals subjected to ICH and treated with hUC- 
MSCs (mICH+hUC-MSC). There were no statistically significant differences between the groups at any time point (Fig. 2A). In contrast, animals subjected to sICH performed significantly worse than sham-operated animals on the rotarod test at the first postsurgery time point, regardless of the treatment (Fig. 2A). Animals from both vehicle- and hUC-MSC-treated sICH groups exhibited performance improvement over time, although there was still a significant difference between the sICH+Vehicle and the shamoperated group on day 7 (Fig. 2A). In addition, animals from the sICH+hUC-MSC group had a slightly better performance than animals from the sICH+Vehicle group on day 20, although it did not reach statistical significance (Fig. 2A). These results indicate that the $\mathrm{mICH}$ model did not result in long-term deficits in the rotarod test, whereas the sICH model induced at least a transient impairment that was not efficiently attenuated by hUC-MSCs.

The elevated body swing test was performed on days 1,8 , 15 , and 21 after surgery, as well as at baseline, for the measurement of asymmetrical motor behavior (Fig. 1). This test revealed that, compared with the sham group, the mICH+Vehicle group had an increased percentage of right-side swings on day 8 , although significant differences were not found at other time points (Fig. 2B). In addition, the elevated body swing test revealed a biased swing activity to the right side in animals from both sICH groups, starting at the first day postsurgery and lasting over the entire surveillance period (Fig. 2B). Statistically significant differences were observed when the percentage of right-side swings was compared between the sICH+Vehicle and the sham group, as well as between the sICH+hUC-MSC and the sham group, on days 1, 8, 15, and 21 after surgery (Fig. 2B). No differences were observed between the sICH+Vehicle and the sICH+hUC-MSC group at any time point (Fig. 2B). Taken together, these results suggest that the cell therapy might prevent a transient alteration in the elevated body swing test after $\mathrm{mICH}$, although there were no significant differences between the $\mathrm{mICH}+\mathrm{Ve}-$ hicle and $\mathrm{mICH}+\mathrm{hUC}-\mathrm{MSC}$ groups. In addition, the elevated body swing test detected persistent impairments after sICH, which were not prevented by the hUC-MSC therapy.
FIG. 2. Functional assessment in models of $\mathrm{mICH}$ and sICH. (A) Latency to fall in the rotarod performance test at different time points from surgery. (B) Percentage of right turns in the elevated body swing test at different time points from surgery. ${ }^{¥}$ Comparison between Sham and mICH+Vehicle groups, *comparisons between Sham and sICH+Vehicle groups, \#comparisons between Sham and sICH+hUC-MSC groups; * or ${ }^{\#} P<0.05$, \#\# or ${ }^{\sharp} P<$ 0.01 , *** or ${ }^{\# \# \# ~} P<0.001$; two-way ANOVA with repeated-measures, Tukey's post hoc test. Data shown in the graphs are means \pm SEM. $n=10$ animals in the Sham group, 9 animals in the $\mathrm{mICH}+$ Vehicle group (8 for the rotarod test), 10 animals in the $\mathrm{mICH}+\mathrm{hUC}-\mathrm{MSC}$ group ( 8 for the rotarod test), 14 animals in the sICH+Vehicle group, and 12 animals in the sICH+hUC-MSC group. ANOVA, analysis of variance; $\mathrm{mICH}$ : moderate intracerebral hemorrhage; sICH: severe intracerebral hemorrhage. Color images are available online.
A $\mathrm{mICH} \quad$ sICH

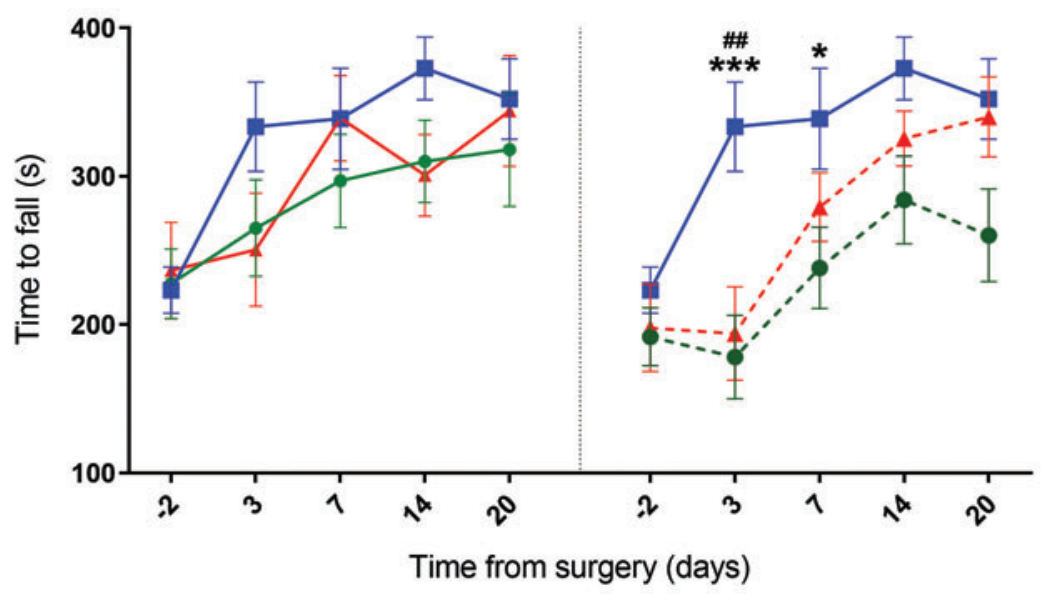

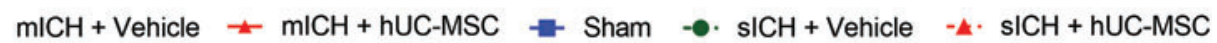

B

$\mathrm{mlCH}$

sICH

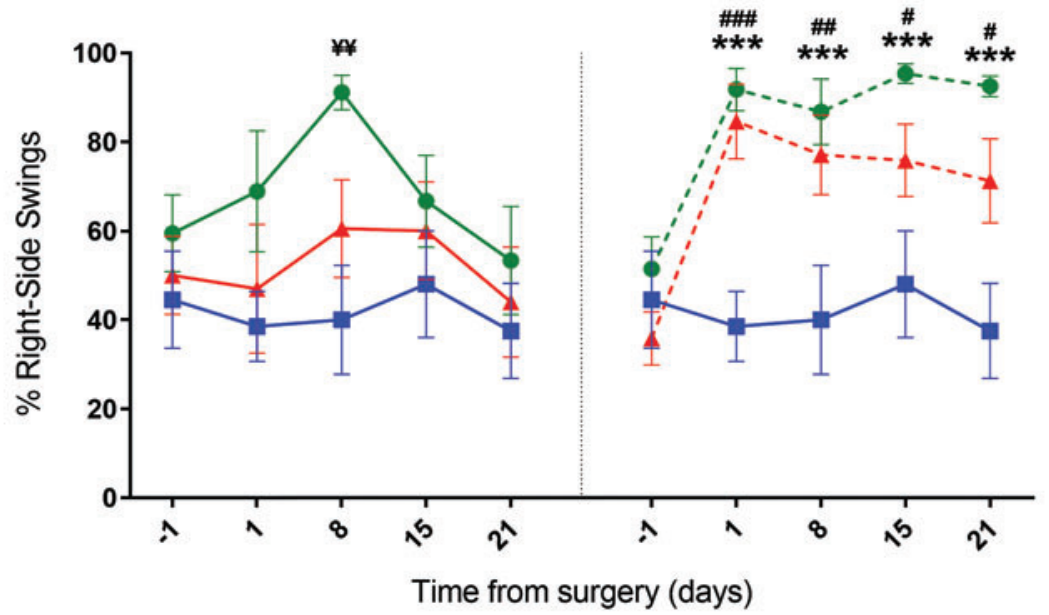

$\mathrm{mICH}+$ Vehicle $\neq \mathrm{mICH}+$ hUC-MSC

Sham

$\mathrm{slCH}+$ Vehicle

sICH + hUC-MSC 


\section{Magnetic resonance imaging}

Quantification of lesion volume on MRI images showed that the residual hematoma volume was significantly smaller in the $\mathrm{mICH}+\mathrm{hUC}-\mathrm{MSC}$ group than in the $\mathrm{mICH}+\mathrm{Vehicle}$ group (Fig. 3A, B). To evaluate hemispheric atrophy, we also quantified the ratio of the volumes of the ipsilateral and contralateral hemispheres, but there was no difference between the two groups (Fig. 3C). In contrast, the residual hematoma volume was not modified by the cell therapy after sICH (Fig. 4A, B). We also quantified the ratio of the volumes of the ipsilateral and contralateral hemispheres, but there was no difference between the two sICH groups (Fig. 4C).

\section{Biodistribution of transplanted cells}

We also evaluated the biodistribution of ${ }^{99 \mathrm{~m}} \mathrm{Tc}-\mathrm{hUC}$ MSCs in different organs during the first $24 \mathrm{~h}$ after transplantation in naïve, sham, mICH, and sICH animals
(Fig. 5A). Whole-body nuclear imaging carried out $2 \mathrm{~h}$ after cell injection indicated activity in the lungs, liver, spleen, and kidneys in all groups (Fig. 5B). Gamma well counting at $24 \mathrm{~h}$ after hUC-MSC injection indicated higher uptake in the lungs, kidneys, spleen, and liver, without significant differences between the experimental groups (Fig. 5C). Although the activity in the brain was very low, we observed greater uptake in the ipsilateral (lesioned) hemisphere in animals subjected to $\mathrm{sICH}$, in comparison with sham-operated rats and naïve animals (Fig. 5D).

\section{Effects of hUC-MSCs on the expression of inflammatory mediators in the brain}

To evaluate the potential immunomodulatory effects of hU-MSCs in the brain, we used a Luminex ${ }^{\circledR}$ assay to quantify the levels of two proinflammatory cytokines (IL-1 $\beta$ and IL-6), an anti-inflammatory cytokine (IL-10), and a chemokine (MCP-1) in the ipsilateral hemisphere $24 \mathrm{~h}$ after
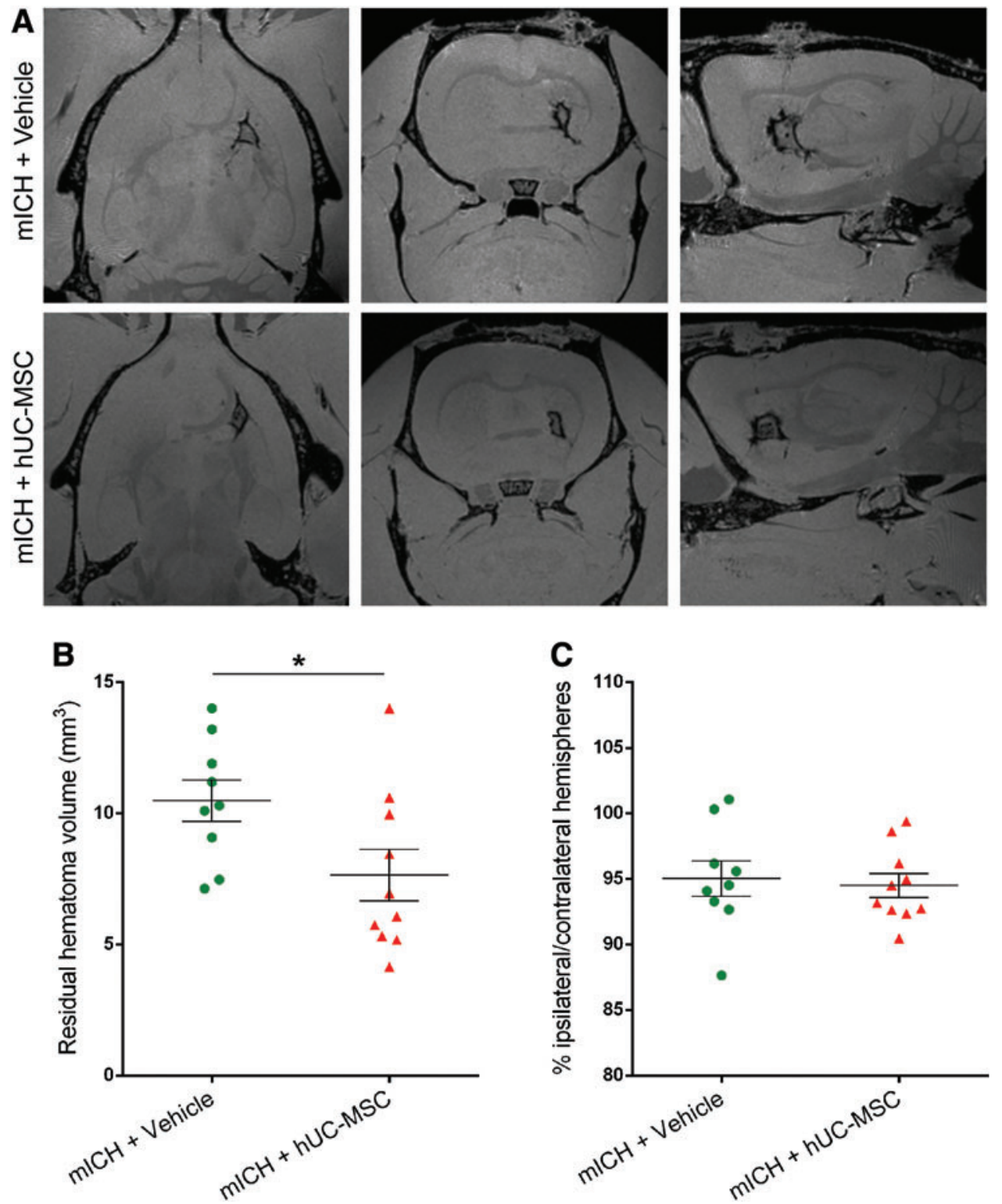

FIG. 3. Animals treated with hUC-MSC had a smaller hematoma volume than vehicle-treated animals after a mICH. (A) Representative T1-weighted images obtained with a $3 \mathrm{D}$ sequence in a 7 Tesla magnetic resonance imaging scanner 22 days after the induction of a $\mathrm{mICH}$. Animals were treated with hUC-MSC (mICH+hUCMSC) or with the vehicle (mICH+Vehicle) $24 \mathrm{~h}$ after the injury. (B, C) Graphs showing the quantification of the residual hematoma volume (B) and the ratio between the volumes of the ipsilateral and contralateral hemispheres (C), respectively. Data shown in the graphs are means \pm SEM. $* P<0.05 ; \quad$ Student's $t$-test. $n=9$ rats in the mICH+Vehicle group and 10 animals in the mICH+hUCMSC group. Color images are available online. 
FIG. 4. hUC-MSC did not modify the residual hematoma volume after a severe intracerebral hemorrhage. (A) Representative T1-weighted images obtained with a 3D netic resonance imaging scanner 22 days after the induction of a severe intracerebral hemorrhage. Animals were treated with hUC-MSC (sICH+hUC-MSC) or with the vehicle (sICH+Vehicle) $24 \mathrm{~h}$ after the injury. (B, C) Graphs showing the quantification of the residual hematoma volume (B) and the ratio between the volumes of the ipsilateral and contralateral hemispheres $(\mathbf{C})$, respectively. Data shown in the graphs are means \pm SEM. Student's $t$-test. $n=14$ rats in the sICH+Vehicle group and MSC group. Color images are available online. sequence in a 2 Tesla mag12 animals in the sICH+hUC-
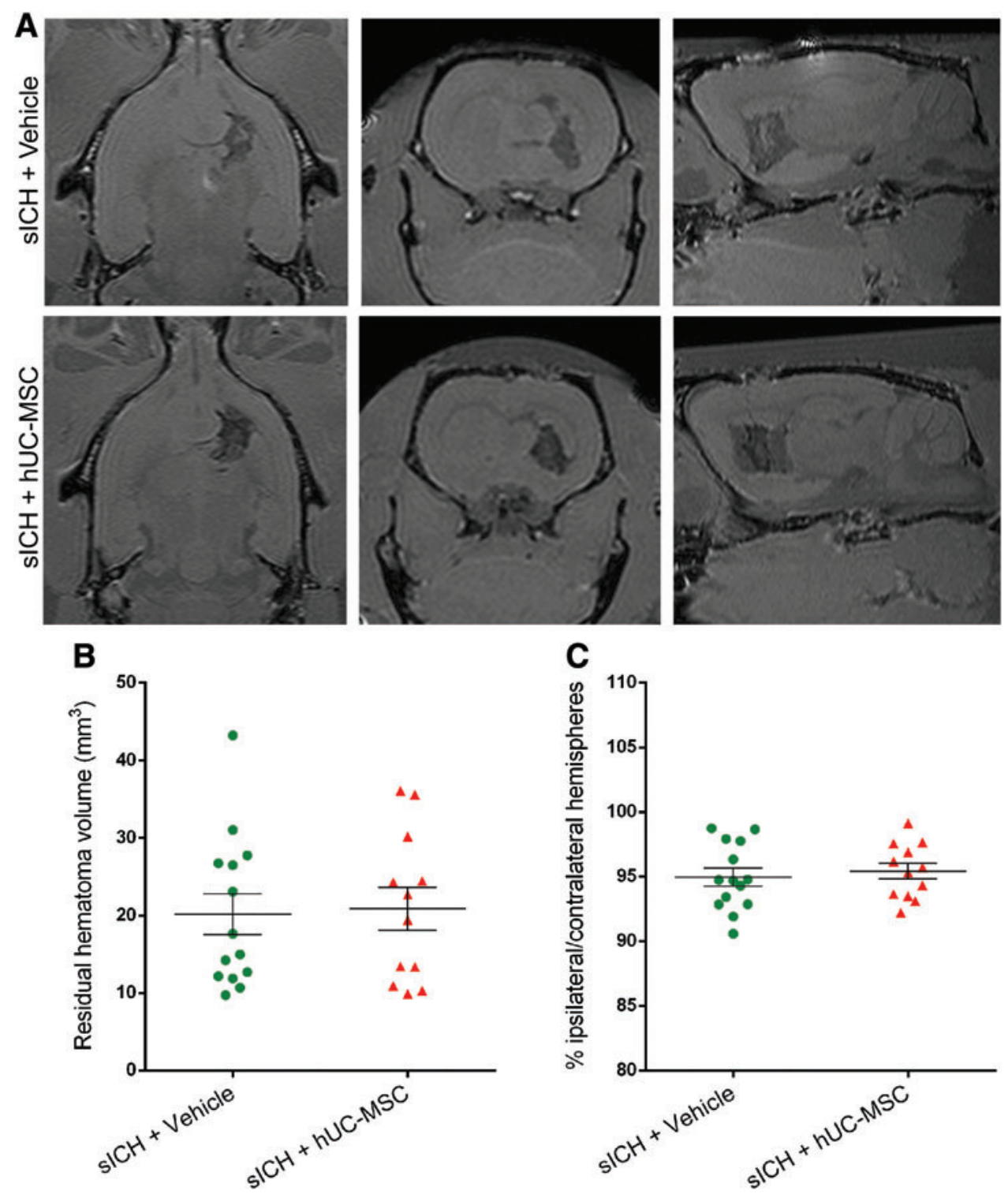

hUC-MSCs transplantation in animals subjected to $\mathrm{mICH}$ or sICH. Sham-operated animals treated with an intravenous injection of the vehicle were used as controls (Fig. 6A). Our results showed that the mICH model did not induce statistically significant changes in the levels of these inflammatory mediators in the brain in comparison with the Sham group. Moreover, the cell therapy did not affect these results (Fig. 6B). In contrast, we observed a statistically significant increase in the levels of MCP-1 in the sICH+Vehicle group in comparison with the Sham group, which was not observed in the sICH+hUC-MSC group (Fig. 6B).

\section{Discussion}

Here, we used MRI to investigate the potential therapeutic effects of the intravenous hUC-MSCs infusion in two models of ICH. One of our main findings was that the residual hematoma volume was smaller in hUC-MSC-treated animals than in animals treated with the vehicle in the $\mathrm{mICH}$ model. In contrast, cell therapy did not change the residual hematoma volume after sICH. These results highlight the importance of studying the effects of novel therapies using more than one model, accounting for differences in the hematoma volume, one of the most important factors influencing outcomes in patients with ICH [37].

To understand the differential effects of hUC-MSCs in both conditions, it will first be necessary to investigate the mechanisms by which MSCs might contribute to hematoma resolution. MSCs have been shown to regulate the function of monocytes, microglia, and macrophages [38,39], cells that play fundamental roles in the processes of hematoma resolution and scar formation [10,40,41]. These immunomodulatory effects can be partly explained by the paracrine action of MSCs. Noh et al. showed that MSC-conditioned media decreased the expression of proinflammatory cytokines by lipopolysaccharide-stimulated microglia, while increasing their phagocytic activity [42]. In addition, MSCsderived extracellular vesicles have been shown to modulate the phenotype of microglia and macrophages in favor of an anti-inflammatory response $[43,44]$, as well as to increase 

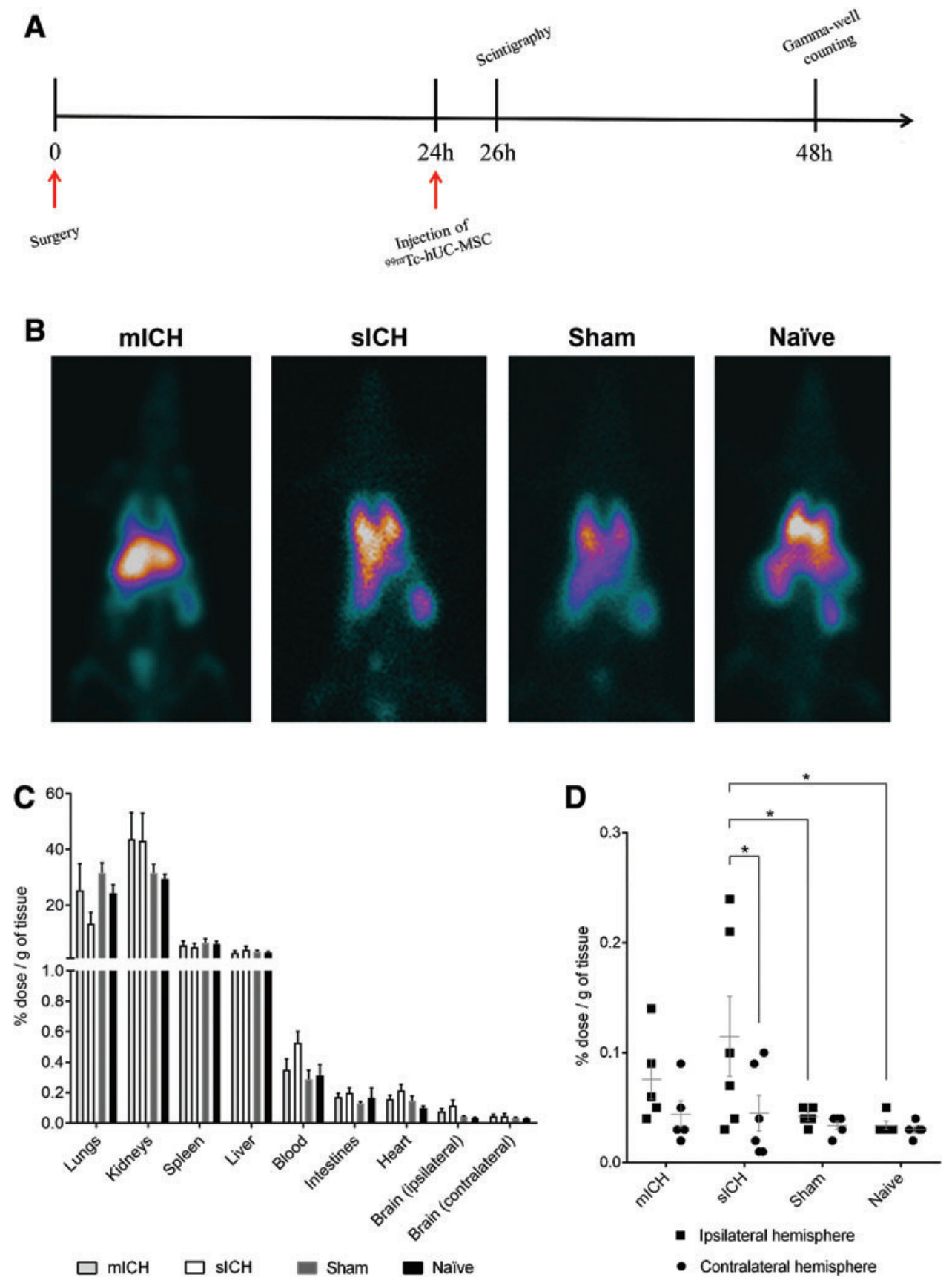

FIG. 5. Biodistribution of transplanted cells. (A) Experimental design. (B) Representative whole-body images demonstrating the biodistribution of ${ }^{99 \mathrm{~m}} \mathrm{Tc}-\mathrm{hUC}-\mathrm{MSC} 2 \mathrm{~h}$ after a single intravenous infusion in rats subjected to collagenase-induced $\mathrm{mICH}$ and $\mathrm{sICH}$, sham-operated animals (Sham), and naïve rats. (C, D) Graphs showing the biodistribution of ${ }^{99 \mathrm{~m}} \mathrm{Tc}-\mathrm{hUC}$ MSC $24 \mathrm{~h}$ after a single intravenous infusion in rats from the different experimental groups. Tracer activity is expressed as the percentage of injected dose per gram of tissue (\% dose/g). Data on the distribution of injected cells in the brain are shown in detail in (D). Data shown in the graphs represent means \pm SEM. $n=5$ or 6 (sICH group) animals per group. Two-way ANOVA, Bonferroni's post hoc test. ${ }^{*} P<0.05 . \quad{ }^{99 \mathrm{~m}} \mathrm{Tc}-\mathrm{hUC}-\mathrm{MSC}$, ${ }^{99 \mathrm{~m}}$ Technetium-labeled human umbilical cord-derived mesenchymal stromal cells. Color images are available online.

the expression of the scavenger receptor CD36 in macrophages [43], a molecule that mediates hematoma absorption after ICH [45]. MSCs could also attenuate the secondary phase of brain injury, which is attributed to the induction of oxidative stress and neuroinflammatory processes by blood products [46]. Several reports have shown that, besides their immunomodulatory actions, MSCs have antioxidant effects [47,48], and that MSCs-derived extracellular vesicles can deliver antioxidant enzymes, including peroxiredoxins [49], catalase [48], and glutathione peroxidase 1 [50], to other cells.

We have also employed two tests to evaluate whether the cell therapy would modify functional outcomes: the rotarod test and the elevated body swing test. None of them was capable of detecting sensorimotor deficits in $\mathrm{mICH}$ animals, except for a transient increase in the percentage of right-side swings at day 8 post-ICH that was at least partially prevented by the cell therapy. Animals with a sICH exhibited enduring deficits in the elevated body swing test. However, these deficits were not ameliorated by hUC-MSCs. Also, the rotarod detected significant impairments in motor coordination after sICH, regardless of the treatment, although animals treated with hUC-MSCs had a slightly better performance (statistically not significant) at the last time point examined. These results are consistent with the findings of Kim et al. [23]; they showed that animals subjected to ICH and treated with an intracerebroventricular injection of hUC-MSCs started to have a better performance in the 


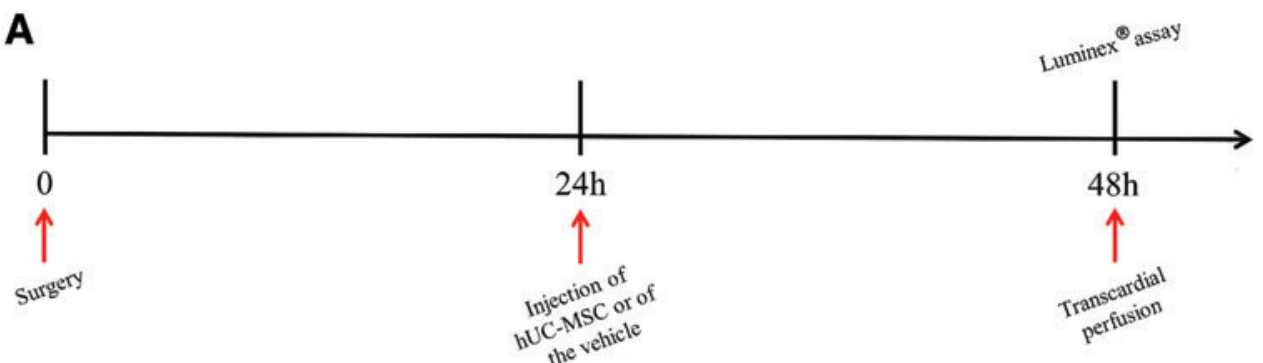

FIG. 6. Effects of hUCMSC on the expression of inflammatory mediators in the brain. (A) Experimental design. Animals were subjected to collagenase-induced $\mathrm{mICH}$ and $\mathrm{sICH}$, respectively, and then were treated with hUC-MSC or with the vehicle $24 \mathrm{~h}$ after the injury. Sham-operated animals treated with an intravenous injection of the vehicle (Sham) were used as controls. A Luminex ${ }^{\circledR}$ assay was used to quantify the levels of IL- $1 \beta$, IL-6, IL-10, and MCP-1 in the brain (ipsilateral hemisphere) $24 \mathrm{~h}$ after the intravenous injection of the cells or of the vehicle. (B) Graphs show individual values and means \pm SEM. $n=6(\mathrm{mICH}+$ Vehicle) or 7 animals per group. One-way ANOVA, Bonferroni's post hoc test. ** $P<0.01$. IL-1 $\beta$, interleukin$1 \beta$; MCP-1, monocyte chemoattractant protein 1. Color images are available online.
B

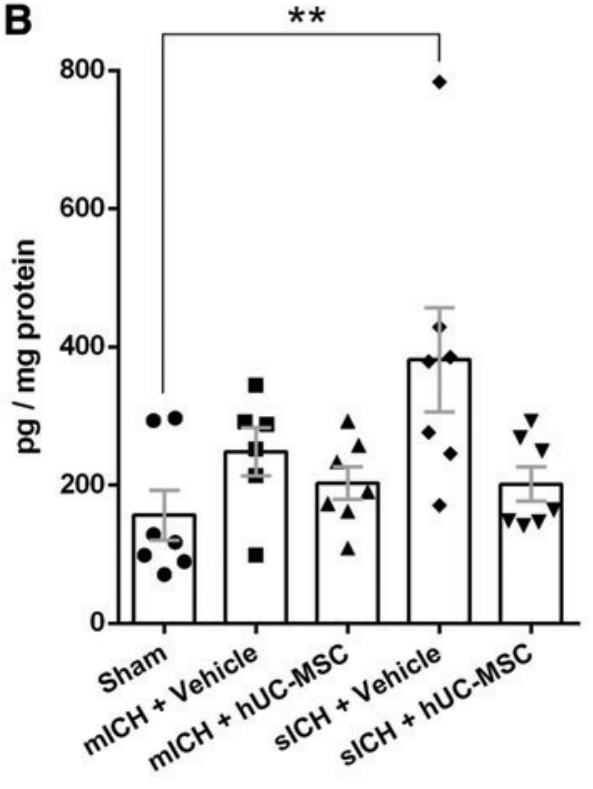

MCP-1
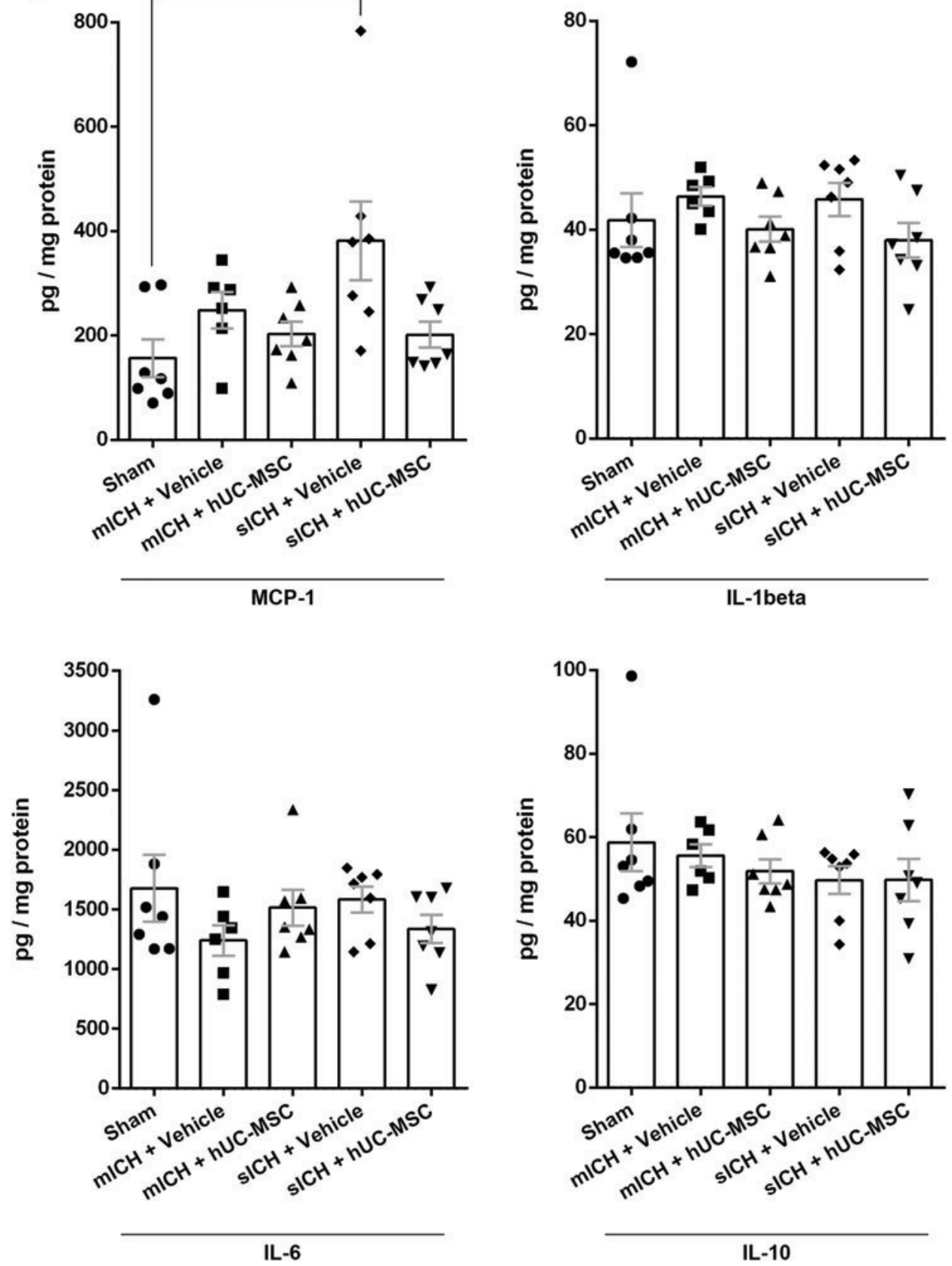

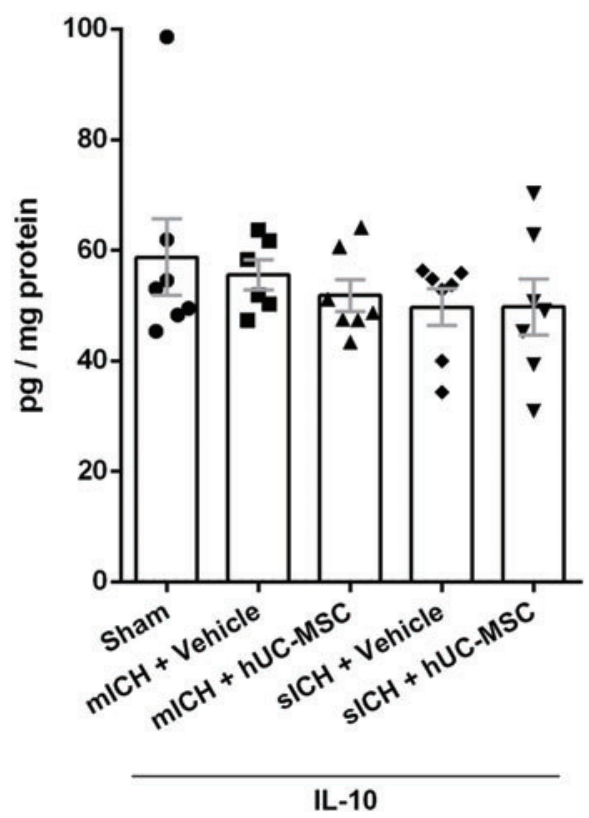

rotarod test only at 4 weeks after transplantation, in comparison with untreated animals. Possible explanations for this delayed effect include the possibility that treated animals presented a greater capacity to learn compensatory strategies to perform the task [51], and/or that the presence of brain edema in the first days after ICH might have acted as a confounding factor [52]. These data indicate that the long-term assessment of the behavioral effects of cell therapies, as well as the utilization of additional behavioral tests, will need to be considered in future studies. Indeed, 
cognitive decline has been recently reported to occur in a model of ICH in mice [53], in contrast to what had been previously observed in rats $[54,55]$.

Our study has limitations, and our findings raise several questions that remain to be investigated. This was an exploratory study that only used male rats, but future larger studies are warranted to investigate whether there are sexrelated differences related to hUC-MSCs-based therapies for ICH. The model of sICH employed in this study had a relatively high mortality rate. However, since almost all deaths occurred in the first $24 \mathrm{~h}$ after collagenase injection (i.e., before the infusion of hUC-MSCs), our experimental design did not allow the assessment of the effects of the cell therapy on the overall survival. In this regard, a recent study found that the intravenous injection of human placentaderived MSCs $1 \mathrm{~h}$ after the injection of collagenase into the striatum of adult rats decreased the mortality rate from $50 \%$ to $8.3 \%$ at $24 \mathrm{~h}$. Moreover, treated animals had smaller hematomas than animals that received the vehicle [56].

Only a single dose of $3 \times 10^{6}$ hUC-MSCs was tested in this study. Although this number of transplanted cells corresponds to the average number of intravenously administered MSCs in previous studies [13,14], dose-escalation studies are still needed. Current data suggest that BM-MSCs improve neurological outcomes in models of hemorrhagic and ischemic stroke but, as long as a minimum number of $\sim 5 \times 10^{5}$ cells are administered, there is no additional benefit from higher cell doses $[14,57]$. However, it is currently unknown whether the same is true for hUC-MSCs. A different behavior of hUC-MSCs cannot be excluded bona fide given, for instance, the observed differences in the expression of genes related to immunomodulatory and proregenerative functions $[16,17]$.

We decided to use freshly thawed cells in this study considering that this is a more likely scenario in future clinical trials, especially if the cells are going to be delivered at acute time points. Freeze-thawing has been shown to decrease the responsiveness of MSCs to interferon- $\gamma$ and to compromise their immunosuppressive capacity in vitro [58,59], but Hoogduijn et al. showed that MSCs exhibited limited gene expression changes after thawing [60]. Freshly thawed MSCs and cells that have been continuously cultured induced a similar pattern of expression of cytokines and chemokines in the lungs of healthy mice [60], and were equally effective in improving several parameters in a model of allergic airway inflammation [61]. Moreover, a recent meta-analysis of preclinical studies that investigated the effects of BM-MSCs in models of ischemic stroke showed that frozen cells were equally or even more effective than fresh cells in improving functional outcomes [57].

Finally, we showed that the percentage of transplanted cells that reached the brain $24 \mathrm{~h}$ after injection was very low. These findings are consistent with the hypothesis that MSCs exert most of their therapeutic actions through the so-called "bystander effects," instead of replacing lost brain cells [62]. It is assumed that these effects include the modulation of local and systemic immune responses [63]. Here, we observed an increase in the expression of MCP-1 in the brain in the sICH+Vehicle group in comparison with the Sham group, which was not observed when the sICH+hUCMSC group was compared with the Sham group, suggesting an immunomodulatory effect of the cell therapy. It was not possible to assess the potential immunomodulatory effects of hUC-MSCs in the model of $\mathrm{mICH}$ since there were no statistically significant differences between the $\mathrm{mICH}+\mathrm{Ve}-$ hicle and the Sham groups, probably because of the late time point chosen (48 h after ICH). Regarding the systemic actions of MSCs, Badner et al., for example, have demonstrated that some of the beneficial effects of hUC-MSCs in a model of traumatic spinal cord injury were not observed in splenectomized mice [64]. Other studies have suggested that the interaction of MSCs with other cells during the pulmonary passage might be an important step for the protection of the blood-brain barrier after a traumatic brain injury [65], or for the regulation of the inflammatory response and the reduction of infarct size in a model of myocardial infarction [66]. Another possibility is that circulating MSCs or MSCs that are trapped in tissue capillaries could release extracellular vesicles into the blood stream. These extracellular vesicles could then act in different organs, including the brain. Indeed, MSCs-derived extracellular vesicles have been shown to have protective effects in models of ICH $[67,68]$. A previous study, however, found no differences when comparing the intravenous and the intracerebral routes for the delivery of human umbilical cord-derived mesenchymal stromal cells in a model of ICH [25]. Nevertheless, it would be interesting to compare the effects of different cell delivery routes and bioengineering approaches that could potentially increase the number of MSCs that reach the brain to the effects of the intravenous route that was used here.

In conclusion, the results presented here indicate that the efficacy of intravenously infused hUC-MSCs in reducing the lesion size after ICH in young adult rats might depend on the volume of the initial hematoma, and that optimization of hUC-MSC-based therapies is therefore necessary. The data on the biodistribution of transplanted cells suggest that a pathway for the understanding of the mechanisms of action of hUC-MSCs in ICH and, consequently, for the improvement of cell therapies, relies on the investigation of the role of local versus systemic effects of hUC-MSCs.

\section{Acknowledgments}

The authors thank the Brazilian funding sources (CAPES, $\mathrm{CNPq}$, and FAPERJ) for granting scholarships that made this study possible. They are grateful to Felipe Marins for technical assistance.

\section{Author Disclosure Statement}

No competing financial interests exist.

\section{Funding Information}

This work was supported by the Departamento de Ciência e Tecnologia (DECIT) do Ministério da Saúde and the Conselho Nacional de Desenvolvimento Científico e Tecnológico (CNPq; 402319/2013-3), the Instituto Nacional de Ciência e Tecnologia em Medicina Regenerativa and the Coordenação de Aperfeiçoamento de Pessoal de Nível Superior (CAPES; 88887.136364/2017-00; and PROBITEC 2262/2012 - 23038.004161/2018-88), and the Fundação de Amparo à Pesquisa do Estado do Rio de Janeiro (FAPERJ; Edital 19/2016). 


\section{References}

1. Feigin VL, B Norrving and GA Mensah. (2017). Global burden of stroke. Circ Res 120:439-448.

2. GBD 2016 Lifetime Risk of Stroke Collaborators, VL Feigin, G Nguyen, K Cercy, CO Johnson, T Alam, PG Parmar, AA Abajobir, KH Abate, et al. (2018). Global, Regional, and Country-Specific Lifetime Risks of Stroke, 1990 and 2016. N Engl J Med 379:2429-2437.

3. Synhaeve NE, RM Arntz, NA Maaijwee, LC RuttenJacobs, HC Schoonderwaldt, LD Dorresteijn, PL de Kort, EJ van Dijk and FE de Leeuw. (2014). Poor long-term functional outcome after stroke among adults aged 18 to 50 years: follow-up of transient ischemic attack and stroke patients and unelucidated risk factor evaluation (FUTURE) study. Stroke 45:1157-1160.

4. Tatlisumak T, B Cucchiara, S Kuroda, SE Kasner and J Putaala. (2018). Nontraumatic intracerebral haemorrhage in young adults. Nat Rev Neurol 14:237-250.

5. Koivunen RJ, J Satopaa, A Meretoja, D Strbian, E Haapaniemi, M Niemela, T Tatlisumak and J Putaala. (2015). Incidence, risk factors, etiology, severity and short-term outcome of non-traumatic intracerebral hemorrhage in young adults. Eur J Neurol 22:123-132.

6. Koivunen RJ, T Tatlisumak, J Satopaa, M Niemela and J Putaala. (2015). Intracerebral hemorrhage at young age: long-term prognosis. Eur J Neurol 22:1029-1037.

7. Baron JC. (2018). Protecting the ischaemic penumbra as an adjunct to thrombectomy for acute stroke. Nat Rev Neurol $14: 325-337$.

8. Hemphill JC, 3rd, SM Greenberg, CS Anderson, K Becker, BR Bendok, M Cushman, GL Fung, JN Goldstein, RL Macdonald, et al. (2015). Guidelines for the management of spontaneous intracerebral hemorrhage: a guideline for healthcare professionals from the American Heart Association/American Stroke Association. Stroke 46:2032-2060.

9. Wilkinson DA, AS Pandey, BG Thompson, RF Keep, Y Hua and G Xi. (2018). Injury mechanisms in acute intracerebral hemorrhage. Neuropharmacology 134:240-248.

10. Zhao X, G Sun, J Zhang, R Strong, W Song, N Gonzales, JC Grotta and J Aronowski. (2007). Hematoma resolution as a target for intracerebral hemorrhage treatment: role for peroxisome proliferator-activated receptor gamma in microglia/macrophages. Ann Neurol 61:352-362.

11. Lan X, X Han, Q Li, QW Yang and J Wang. (2017). Modulators of microglial activation and polarization after intracerebral haemorrhage. Nat Rev Neurol 13:420-433.

12. Rosado-de-Castro PH, PM Pimentel-Coelho, LM da Fonseca, GR de Freitas and R Mendez-Otero. (2013). The rise of cell therapy trials for stroke: review of published and registered studies. Stem Cells Dev 22:2095-2111.

13. Turnbull MT, AC Zubair, JF Meschia and WD Freeman. (2019). Mesenchymal stem cells for hemorrhagic stroke: status of preclinical and clinical research. NPJ Regen Med 4:10.

14. Rosado-de-Castro PH, FG de Carvalho, GR de Freitas, R Mendez-Otero and PM Pimentel-Coelho. (2016). Review of preclinical and clinical studies of bone marrow-derived cell therapies for intracerebral hemorrhage. Stem Cells Int 2016:4617983.

15. Dalous J, J Larghero and O Baud. (2012). Transplantation of umbilical cord-derived mesenchymal stem cells as a novel strategy to protect the central nervous system: technical aspects, preclinical studies, and clinical perspectives. Pediatr Res 71:482-490.
16. Donders R, JFJ Bogie, S Ravanidis, P Gervois, M Vanheusden, R Maree, M Schrynemackers, HJM Smeets, J Pinxteren, et al. (2018). Human Wharton's jelly-derived stem cells display a distinct immunomodulatory and proregenerative transcriptional signature compared to bone marrow-derived stem cells. Stem Cells Dev 27:65-84.

17. Barrett AN, CY Fong, A Subramanian, W Liu, Y Feng, M Choolani, A Biswas, JC Rajapakse and A Bongso. (2019). Human Wharton's jelly mesenchymal stem cells show unique gene expression compared with bone marrow mesenchymal stem cells using single-cell RNAsequencing. Stem Cells Dev 28:196-211.

18. Romanov YA, NE Volgina, VV Vtorushina, AY Romanov, TN Dugina, NV Kabaeva and GT Sukhikh. (2019). Comparative analysis of secretome of human umbilical cordand bone marrow-derived multipotent mesenchymal stromal cells. Bull Exp Biol Med 166:535-540.

19. Pires AO, B Mendes-Pinheiro, FG Teixeira, SI Anjo, S Ribeiro-Samy, ED Gomes, SC Serra, NA Silva, B Manadas, N Sousa and AJ Salgado. (2016). Unveiling the differences of secretome of human bone marrow mesenchymal stem cells, adipose tissue-derived stem cells, and human umbilical cord perivascular cells: a proteomic analysis. Stem Cells Dev 25:1073-1083.

20. Hsieh JY, HW Wang, SJ Chang, KH Liao, IH Lee, WS Lin, $\mathrm{CH} \mathrm{Wu}, \mathrm{WY}$ Lin and SM Cheng. (2013). Mesenchymal stem cells from human umbilical cord express preferentially secreted factors related to neuroprotection, neurogenesis, and angiogenesis. PLoS One 8:e72604.

21. Moll G, JA Ankrum, J Kamhieh-Milz, K Bieback, O Ringden, HD Volk, S Geissler and P Reinke. (2019). Intravascular mesenchymal stromal/stem cell therapy product diversification: time for new clinical guidelines. Trends Mol Med 25:149-163.

22. Zhang Q, X Shang, M Hao, M Zheng, Y Li, Z Liang, Y Cui and Z Liu. (2015). Effects of human umbilical cord mesenchymal stem cell transplantation combined with minimally invasive hematoma aspiration on intracerebral hemorrhage in rats. Am J Transl Res 7:2176-2186.

23. Kim K, HW Park, HE Moon, JW Kim, S Bae, JW Chang, W Oh, YS Yang and SH Paek. (2015). The effect of human umbilical cord blood-derived mesenchymal stem cells in a collagenase-induced intracerebral hemorrhage rat model. Exp Neurobiol 24:146-155.

24. Liao W, J Zhong, J Yu, J Xie, Y Liu, L Du, S Yang, P Liu, J $\mathrm{Xu}$, et al. (2009). Therapeutic benefit of human umbilical cord derived mesenchymal stromal cells in intracerebral hemorrhage rat: implications of anti-inflammation and angiogenesis. Cell Physiol Biochem 24:307-316.

25. Xie J, B Wang, L Wang, F Dong, G Bai and Y Liu. (2016). Intracerebral and intravenous transplantation represents a favorable approach for application of human umbilical cord mesenchymal stromal cells in intracerebral hemorrhage rats. Med Sci Monit 22:3552-3561.

26. Boltze J, A Arnold, P Walczak, J Jolkkonen, L Cui and DC Wagner. (2015). The dark side of the force - constraints and complications of cell therapies for stroke. Front Neurol 6:155.

27. Semple BD, K Blomgren, K Gimlin, DM Ferriero and LJ Noble-Haeusslein. (2013). Brain development in rodents and humans: identifying benchmarks of maturation and vulnerability to injury across species. Prog Neurobiol 106-107:1-16.

28. Rosenberg GA, S Mun-Bryce, M Wesley and M Kornfeld. (1990). Collagenase-induced intracerebral hemorrhage in rats. Stroke 21:801-807. 
29. Kirby ED, K Jensen, KA Goosens and D Kaufer. (2012). Stereotaxic surgery for excitotoxic lesion of specific brain areas in the adult rat. J Vis Exp 65:e4079.

30. Del Bigio MR, HJ Yan, R Buist and J Peeling. (1996). Experimental intracerebral hemorrhage in rats. Magnetic resonance imaging and histopathological correlates. Stroke 27:2312-2319.

31. MacLellan C, A Shuaib and F Colbourne. (2002). Failure of delayed and prolonged hypothermia to favorably affect hemorrhagic stroke in rats. Brain Res 958:192-200.

32. Alencar AKN, PM Pimentel-Coelho, GC Montes, MMC da Silva, LVP Mendes, TL Montagnoli, AMS Silva, JF Vasques, PH Rosado-de-Castro, et al. (2018). Human mesenchymal stem cell therapy reverses Su5416/hypoxia-induced pulmonary arterial hypertension in mice. Front Pharmacol 9:1395.

33. Yaochite JN, C Caliari-Oliveira, LE de Souza, LS Neto, PV Palma, DT Covas, KC Malmegrim, JC Voltarelli and EA Donadi. (2015). Therapeutic efficacy and biodistribution of allogeneic mesenchymal stem cells delivered by intrasplenic and intrapancreatic routes in streptozotocininduced diabetic mice. Stem Cell Res Ther 6:31.

34. Borlongan CV and PR Sanberg. (1995). Elevated body swing test: a new behavioral parameter for rats with 6hydroxydopamine-induced hemiparkinsonism. J Neurosci 15:5372-5378.

35. Ingberg E, J Gudjonsdottir, E Theodorsson, A Theodorsson and JO Strom. (2015). Elevated body swing test after focal cerebral ischemia in rodents: methodological considerations. BMC Neurosci 16:50.

36. Vasconcelos-dos-Santos A, PH Rosado-de-Castro, SA Lopes de Souza, J da Costa Silva, AB Ramos, G Rodriguez de Freitas, LM Barbosa da Fonseca, B Gutfilen and R Mendez-Otero. (2012). Intravenous and intra-arterial administration of bone marrow mononuclear cells after focal cerebral ischemia: is there a difference in biodistribution and efficacy? Stem Cell Res 9:1-8.

37. LoPresti MA, SS Bruce, E Camacho, S Kunchala, BG Dubois, E Bruce, G Appelboom and ES Connolly, Jr. (2014). Hematoma volume as the major determinant of outcomes after intracerebral hemorrhage. J Neurol Sci 345: 3-7.

38. Weiss ARR and MH Dahlke. (2019). Immunomodulation by mesenchymal stem cells (MSCs): mechanisms of action of living, apoptotic, and dead MSCs. Front Immunol 10: 1191.

39. Giunti D, B Parodi, C Usai, L Vergani, S Casazza, S Bruzzone, G Mancardi and A Uccelli. (2012). Mesenchymal stem cells shape microglia effector functions through the release of CX3CL1. Stem Cells 30:2044-2053.

40. Zhao X, J Grotta, N Gonzales and J Aronowski. (2009). Hematoma resolution as a therapeutic target: the role of microglia/macrophages. Stroke 40:S92-S94.

41. Chang CF, BA Goods, MH Askenase, MD Hammond, SC Renfroe, AF Steinschneider, MJ Landreneau, Y Ai, HE Beatty, et al. (2018). Erythrocyte efferocytosis modulates macrophages towards recovery after intracerebral hemorrhage. J Clin Invest 128:607-624.

42. Noh MY, SM Lim, K-W Oh, K-A Cho, J Park, K-S Kim, S-J Lee, M-S Kwon and SH Kim. (2016). Mesenchymal stem cells modulate the functional properties of microglia via TGF- $\beta$ secretion. Stem Cells Transl Med 5:1538-1549.

43. Lo Sicco C, D Reverberi, C Balbi, V Ulivi, E Principi, L Pascucci, P Becherini, MC Bosco, L Varesio, et al. (2017).
Mesenchymal stem cell-derived extracellular vesicles as mediators of anti-inflammatory effects: endorsement of macrophage polarization. Stem Cells Transl Med 6:1018-1028.

44. Jaimes Y, Y Naaldijk, K Wenk, C Leovsky and F Emmrich. (2017). Mesenchymal stem cell-derived microvesicles modulate lipopolysaccharides-induced inflammatory responses to microglia cells. Stem Cells 35:812-823.

45. Fang H, J Chen, S Lin, $\mathrm{P}$ Wang, Y Wang, X Xiong and Q Yang. (2014). CD36-mediated hematoma absorption following intracerebral hemorrhage: negative regulation by TLR4 signaling. J Immunol 192:5984-5992.

46. Mracsko E and R Veltkamp. (2014). Neuroinflammation after intracerebral hemorrhage. Front Cell Neurosci 8:388.

47. Cui Y, S Ma, C Zhang, W Cao, M Liu, D Li, P Lv, Q Xing, R Qu, et al. (2017). Human umbilical cord mesenchymal stem cells transplantation improves cognitive function in Alzheimer's disease mice by decreasing oxidative stress and promoting hippocampal neurogenesis. Behav Brain Res 320:291-301.

48. de Godoy MA, LM Saraiva, LRP de Carvalho, A Vasconcelos-Dos-Santos, HJV Beiral, AB Ramos, LRP Silva, RB Leal, VHS Monteiro, et al. (2018). Mesenchymal stem cells and cell-derived extracellular vesicles protect hippocampal neurons from oxidative stress and synapse damage induced by amyloid-beta oligomers. J Biol Chem 293:1957-1975.

49. Liu S, V Mahairaki, H Bai, Z Ding, J Li, KW Witwer and L Cheng. (2019). Highly purified human extracellular vesicles produced by stem cells alleviate aging cellular phenotypes of senescent human cells. Stem Cells 37:779-790.

50. Yan Y, W Jiang, Y Tan, S Zou, H Zhang, F Mao, A Gong, $\mathrm{H}$ Qian and W Xu. (2017). hucMSC exosome-derived GPX1 is required for the recovery of hepatic oxidant injury. Mol Ther 25:465-479.

51. Cui L-1, D Golubczyk and J Jolkkonen. (2017). Top 3 behavioral tests in cell therapy studies after stroke. Stroke 48: 3165-3167.

52. MacLellan CL, R Paquette and F Colbourne. (2012). A critical appraisal of experimental intracerebral hemorrhage research. J Cereb Blood Flow Metab 32:612-627.

53. Shi E, K Shi, S Qiu, KN Sheth, MT Lawton and AF Ducruet. (2019). Chronic inflammation, cognitive impairment, and distal brain region alteration following intracerebral hemorrhage. FASEB J 33:9616-9626.

54. Hartman R, T Lekic, H Rojas, J Tang and JH Zhang. (2009). Assessing functional outcomes following intracerebral hemorrhage in rats. Brain Res 1280:148-157.

55. MacLellan CL, KD Langdon, KP Churchill, S GranterButton and D Corbett. (2009). Assessing cognitive function after intracerebral hemorrhage in rats. Behav Brain Res 198:321-328.

56. Choi BY, OJ Kim, SH Min, JH Jeong, SW Suh and TN Chung. (2018). Human placenta-derived mesenchymal stem cells reduce mortality and hematoma size in a rat intracerebral hemorrhage model in an acute phase. Stem Cells Int 2018:1658195.

57. Satani N, C Cai, K Giridhar, D McGhiey, S George, K Parsha, DM Nghiem, KS Valenzuela, J Riecke, FS Vahidy and SI Savitz. (2019). World-wide efficacy of bone marrow derived mesenchymal stromal cells in preclinical ischemic stroke models: systematic review and meta-analysis. Front Neurol 10:405.

58. Moll G, JJ Alm, LC Davies, L von Bahr, N Heldring, L Stenbeck-Funke, OA Hamad, R Hinsch, L Ignatowicz, 
et al. (2014). Do cryopreserved mesenchymal stromal cells display impaired immunomodulatory and therapeutic properties? Stem Cells 32:2430-2442.

59. Francois M, IB Copland, S Yuan, R Romieu-Mourez, EK Waller and J Galipeau. (2012). Cryopreserved mesenchymal stromal cells display impaired immunosuppressive properties as a result of heat-shock response and impaired interferon-gamma licensing. Cytotherapy 14:147-152.

60. Hoogduijn MJ, SF de Witte, F Luk, MC van den Hout-van Vroonhoven, L Ignatowicz, R Catar, T Strini, SS Korevaar, IWF van, et al. (2016). Effects of freeze-thawing and intravenous infusion on mesenchymal stromal cell gene expression. Stem Cells Dev 25:586-597.

61. Cruz FF, ZD Borg, M Goodwin, D Sokocevic, D Wagner, DH McKenna, PR Rocco and DJ Weiss. (2015). Freshly thawed and continuously cultured human bone marrowderived mesenchymal stromal cells comparably ameliorate allergic airways inflammation in immunocompetent mice. Stem Cells Transl Med 4:615-624.

62. Janowski M, DC Wagner and J Boltze. (2015). Stem cellbased tissue replacement after stroke: factual necessity or notorious fiction? Stroke 46:2354-2363.

63. Salinas Tejedor L, G Berner, K Jacobsen, V Gudi, N Jungwirth, F Hansmann, S Gingele, CK Prajeeth, W Baumgartner, et al. (2015). Mesenchymal stem cells do not exert direct beneficial effects on CNS remyelination in the absence of the peripheral immune system. Brain Behav Immun 50:155-165.

64. Badner A, J Hacker, J Hong, M Mikhail, R Vawda and MG Fehlings. (2018). Splenic involvement in umbilical cord matrix-derived mesenchymal stromal cell-mediated effects following traumatic spinal cord injury. J Neuroinflammation 15:219.

65. Menge T, Y Zhao, J Zhao, K Wataha, M Gerber, J Zhang, P Letourneau, J Redell, L Shen, et al. (2012). Mesenchymal stem cells regulate blood-brain barrier integrity through
TIMP3 release after traumatic brain injury. Sci Transl Med 4:161ra150.

66. Lee RH, AA Pulin, MJ Seo, DJ Kota, J Ylostalo, BL Larson, L Semprun-Prieto, P Delafontaine and DJ Prockop. (2009). Intravenous hMSCs improve myocardial infarction in mice because cells embolized in lung are activated to secrete the anti-inflammatory protein TSG-6. Cell Stem Cell 5:54-63.

67. Otero-Ortega L, MC Gómez de Frutos, F Laso-García, B Rodríguez-Frutos, E Medina-Gutiérrez, JA López, J Vázquez, E Díez-Tejedor and M Gutiérrez-Fernández. (2018). Exosomes promote restoration after an experimental animal model of intracerebral hemorrhage. J Cereb Blood Flow Metab 38:767-779.

68. Han Y, D Seyfried, Y Meng, D Yang, L Schultz, M Chopp and D Seyfried. (2018). Multipotent mesenchymal stromal cell-derived exosomes improve functional recovery after experimental intracerebral hemorrhage in the rat. $\mathrm{J}$ Neurosurg 131:290-300.

$$
\begin{array}{r}
\text { Address correspondence to: } \\
\text { Pedro Moreno Pimentel-Coelho } \\
\text { Instituto de Biofísica Carlos Chagas Filho } \\
\text { Universidade Federal do Rio de Janeiro } \\
\text { Av. Carlos Chagas Filho 373, Prédio do CCS, } \\
\text { Bloco G, Sala G2-001, RJ } \\
\text { Rio de Janeiro 21941-902 } \\
\text { Brazil } \\
\text { E-mail: pedrompc@biof.ufrj.br }
\end{array}
$$

Received for publication August 13, 2019 Accepted after revision March 11, 2020

Prepublished on Liebert Instant Online March 11, 2020 